\title{
INCONGRUENCIAS DE LAS SANCIONES A GRUPOS ARMADOS ILEGALES CONTEMPLADOS EN LOS ACUERDOS DE LA HABANA CON LOS MODELOS DE JUSTICIA RESTAURATIVA ACTUALES
}

Inconsistencies of sanctions to illegal armed groups referred in the Havana agreements with the current restorative justice models

Fecha de recepción: 12 de octubre de 2017

Fecha de aceptación: 21 de noviembre de 2017

SUMARIO: 1. Introducción; 2. Metodología; 3. En contexto; 4. Que es la justicia restaurativa; 5. Principios de la justicia restaurativa; 6 . Características de los programas de justicia restaurativa; 7. Contraparte constitucional; 8. Que dice la jurisprudencia internacional; 9. El Acuerdo Final Para La Terminación Del Conflicto y La Construcción De Una Paz Estable y Duradera (Acuerdos De La Habana); 10. Conclusiones; 11. Bibliografía; 12. Tabla anexo 1 


\section{COMO SE CITA ESTE ARTÍCULO (APA 6)}

Campiz Jiménez, Gustavo (2018). Incongruencias de las sanciones a grupos armados ilegales contemplados en los acuerdos de la Habana con los modelos de justicia restaurativa actuales. Revista Jurídica Mario Alario D’Filippo, Vol. X Nº 19 pág. 178-203

\section{RESUMEN}

El cambio de un modelo de Justicia Retributiva a uno de justicia restaurativa es necesario, si lo que se quiere es poner fin a un conflicto social envuelto en una espiral de violencia arraigada por décadas, para reconstruir tejido social y lograr una paz estable y duradera. Es menester que la justicia conozca a fondo los hechos y las personas, pero que este inclinada siempre a favor de la víctima, con una participación real, activa y a su vez que brinde oportunidades al victimario a través de la reparación, y el perdón que brinda la víctima para que logre pertenecer nuevamente al tejido social y así superar el estigma del delito.

\section{Palabras Claves}

Justicia retributiva, justicia restaurativa, victima, reconstrucción, tejido social, perdón.

\section{ABTRACT}

The change from a model of Retributive Justice to a restorative justice model is necessary, if what is wanted is to end a social conflict wrapped in a spiral of violence rooted for decades, to rebuild the social fabric and achieve a stable and lasting peace. It is necessary that the justice knows thoroughly the facts and the people, but that always inclined in favor of the victim, with a real, active participation and also provides opportunities to the victimizer through the reparation, and forgiveness that provides the victim to be able to belong again to the social fabric and overcome the stigma of crime.

\section{Keywords}

Retributive justice, restorative justice, victim, reconstruction, social fabric. 


\section{INTRODUCCIÓN}

En la corta historia del Estado colombiano, se han adelantado diferentes procesos de paz, algunos de los cuales han arrojado resultados satisfactorios como el del M-19. Sin embargo, otros, como los del Gobierno y las FARC, van a paso lento, por las posiciones intransigentes asumidas por los negociadores. Y lo complejo del contexto del conflicto y el nuevo enfoque de justicia restaurativa requerido para adelantarlo. Actualmente, el Gobierno afronta duros cuestionamientos por cuenta del acuerdo de paz con la guerrilla más antigua de sud américa, que hace presencia a lo largo de todo el territorio nacional y también internacional, Lo que ha generado toda una serie de inquietudes e inconformismos entre los diferentes sectores de la sociedad civil, ONG, defensores de los derechos humanos entre otros, que han puesto en tela de juicio el citado, proceso por falta de un mínimo de garantías para llevar a cabo su cometido por parte del Estado y las Farc.

Estos cuestionamientos tienen su asidero en el enfoque retributivo de la justicia actual, el cual se ha centrado básicamente en el delito, definiéndolo como una violación de la norma y donde la victima pasa a ser un mero testigo. En una sociedad como la colombiana, donde los grados de impunidad son escandalosos ya sea por la corrupción o la inoperancia del sistema actual, el ciudadano cada que ocurre un delito clama por penas más severas donde el castigo al culpable (el victimario) se ha convertido en una obsesión social saciando la sed de venganza del pueblo. Pero abandonando a la víctima y las razones sociales del delito. Contrario sensu la justicia restaurativa cambia su perspectiva respecto de la justicia formal en varios aspectos a) el principal eje es la víctima, no el victimario; b) así pues el eje central es la reparación de la víctima, pero con la participación del victimario. (Márquez Cárdenas, 2007)

El cambio de un modelo retributivo a uno restaurativo es necesario, si lo que se quiere es poner fin a un conflicto social envuelto en una espiral de violencia arraigada por décadas, para reconstruir tejido social y lograr una paz estable y duradera. Es menester que la justicia conozca a fondo los hechos y las personas, pero que este inclinada siempre a favor de la víctima, con una participación real, activa y a su vez que brinde oportunidades al victimario a través de la reparación, y el perdón que brinda la víctima para que logre pertenecer nuevamente al tejido social y así superar el estigma del delito.

No se puede desconocer que en Colombia se han dado pasos significativos en este tema como son; la ley de justicia y paz del 2005, la ley 1448 del 2011 o ley de víctimas y ahora la refrendación de los acuerdos de la Habana que cursan trámite en el congreso. Pero esta transición dentro de un proceso penal acorde con la búsqueda de la anhelada paz responde a varios factores como las nuevas formas delictivas y la necesidad de un modelo de transición para la reincorporación de combatientes de grupos armados que no se podría llevar a cabo con el modelo penal retributivo 
actual, así mismo juega un papel importante el descontento social por el retardo e incertidumbre de la administración de justicia las que exigen del Estado respuestas creativas y efectivas. (Sistema Nacional de Seguridad Ciudadana (SINASEC) \& APOYO Opinión y Mercado, 2005).

Sumado a esto las respuestas tradicionales del aparato represor penal del Estado mediante la imposición de la pena, nunca han podido ir a la raíz del conflicto social desencadenado por la comisión del delito, ya que, la pena calma el clamor de venganza de la sociedad, pero no resuelve dicho conflicto social. (Zuñiga Rodriguez, 2006)

\section{Metodología}

El presente trabajo de investigación se encuentra enmarcado en un tipo de investigación teórico jurídico, dado que se pretende establecer las implicaciones jurídicas que se presenta en el tratamiento de Las sanciones aplicables a quienes reconozcan verdad exhaustiva, detallada y plena en sala de reconocimiento de verdad y responsabilidad en zonas rurales, dentro de los acuerdos de la habana, en acuerdos de paz, específicamente en el contexto de la justicia restaurativa dentro de las penas alternativas a crímenes sufridos por parte de la población víctima del conflicto armado interno en Colombia.

En cuanto a la forma de investigación, acorde con lo explicitado en el párrafo anterior, se ubica en una forma de investigación Exploratoria, pues se pretende dar razones de los niveles satisfacción, empoderamiento a las víctimas y efectividad que posee la Justicia Restaurativa contemplada en las sanciones alternativas para delitos cometidos contra las víctimas del conflicto armado colombiano, tanto de las Farc como del estado.

\section{En contexto}

Para la filosofía el significado de Justicia varia de autor en autor, por ejemplo, par Platón sostenía que el individuo debía salir de la oscuridad, de la caverna del desconocimiento, así pues, la persona se hace justa en la medida que adquiere conocimiento, por tanto, quien adquiere más conocimiento se hace más justo, lo que se traduce en que los gobernantes deben tener amplios conocimientos para saber gobernar y para realmente hacer justicia. Aristóteles define la justicia como dar a cada ciudadano lo que corresponde según sus necesidades y aportes en la sociedad. Por su parte Kant manifestaba que la justicia de un Estado debía velar por tres principios fundamentales; La Libertad De Los Individuos, la igualdad entre ellos y La independencia de cada Miembro De una comunidad. Más contemporáneamente Kelsen argumento que la justicia era un derecho natural que prevalecía sobre el derecho positivo ya que si este va en contravía de los derechos fundamentales del ser humano no se puede hablar de justicia. Por lo que para efectos de este artículo se debe enfocar en una de dos vertientes bien definidas como son el modelo retributivo y el modelo restaurativo. Un modelo retributivo imperante durante mucho tiempo, 
que se fundamenta en la ley del talión, en el juicio de responsabilidad y en el castigo al victimario. Y otro y tema de este artículo el modelo el restaurativo que por el contrario se centra en la victima bajo un sistema dialógico, de restauración del tejido social, en base a un perdón reconciliador.

El perdón y la reconciliación con más éxito se dan cuando los hijos de la víctima y los del victimario conviven en paz y en unidad. (PASCUAL, 2012) "señaló que la existencia de las naciones dependía del perdón. Cada nación representa una amalgama de tribus que, durante años, o quizás cientos de años, se han infringido unas a otras, todo tipo de sufrimientos y desdichas. Pero eso no destruye la conciencia de un destino común. Cuando el crimen solo lo comete una de las partes, es la extrema humillación y la persecución despiadada. En ambos casos se produce una "desactualización" intencionada con el fin de liberar al presente y, más especialmente, al futuro de la pesada carga del pasado. $Y$ como todos somos culpables, todos podemos ser libres."

\section{Que es la justicia restaurativa}

El movimiento de las alternativas a prisión es demasiado complejo para poder hablar de él, de manera singular. No obstante para sintetizar, se puede decir que detrás del surgimiento de las alternativas a prisión existen dos razones principales; reducir el encarcelamiento (en atención a considerar que es muy caro, y genera un sufrimiento innecesario a delincuentes de baja peligrosidad o que es contraproducente desde el punto de vista de la prevención especial) y rehabilitar al delincuente. (CID MOLINE, 2009)

En este sentido, los esquemas de la Justicia Retributiva vinculan estrechamente los fines de la pena en sí misma, lo que importa es dar un mensaje al sancionado, a posibles infractores y a la sociedad, bajo los tradicionales criterios de prevención especial y general. Así, la víctima del delito es olvidada y solo se recuerda de ella en la reparación civil este modelo por obvias razones no resulta provechos para resolver el conflicto social subyacente.

Se puede concluir que la justicia restaurativa se apoya en los movimientos de las víctimas ${ }^{51}$ que se empoderan del proceso reclamando más atención dentro del proceso penal para que no solo sean tenidos en cuenta dentro del proceso, sino que a su vez en la orientación de la pena para reivindicación de esta. Orientación está bien diferente a la actual política criminal expansionista que utiliza, manipula y se escuda en una víctima en abstracto a la que atribuye demandas vengativas -apoyándose en alarmas sociales eficazmente orquestadas- que sirve de coartada demagógica para la implantación de incrementos punitivos que no son sino cortinas de humo para ocultar su propia ineficacia en la prevención real de los delitos (PASCUAL, 2012)

\footnotetext{
${ }^{51}$ La Ley "LEY 1448 DE 2011 (junio 10) ARTíCULO 3․ VÍCTIMAS. Se consideran víctimas, para los efectos de esta ley, aquellas personas que individual o colectivamente hayan sufrido un daño por hechos ocurridos a partir del 10 de enero de 1985, como consecuencia de infracciones al Derecho Internacional Humanitario o de violaciones graves y manifiestas a las normas internacionales de Derechos Humanos, ocurridas con ocasión del conflicto armado interno
} 
Por lo tanto, toda pena que no proceda de la absoluta necesidad, dice Montesquieu, es tiránica; proposición que puede hacerse más general de esta manera: todo acto de autoridad ejercido por un hombre que no proceda de la absoluta necesidad es tiránico. He aquí pues, la base sobre la que sustenta el derecho del soberano a castigar los delitos: la necesidad de defender el conjunto de la salud pública frente a las usurpaciones particulares; y tanto más justas serán las penas, cuanto más sagrada e inviolable sea la seguridad y mayor libertad en que el soberano conserva a sus súbditos.

Entonces es por fuerza concluir que de lo expuesto hasta aquí que el fin de la pena no es atormentar ni afligir a un ser sensible ni deshacer un delito ya cometido. Un cuerpo político, que, muy lejos de obrar por pasión, es el moderador tranquilo de las pasiones de cada uno, ¿puede abrigar esa crueldad inútil, instrumento propio del furor, del fanatismo o de los débiles tiranos? ¿Podrían acaso los clamores de un desgraciado arrancar un hecho, ya consumado, al tiempo, que no retrocede nunca? El fin, pues, no es otro que impedir al reo dañar nuevamente a sus conciudadanos, y apartar a sus iguales. Por lo tanto, deberán escogerse aquellas penas y aquel método de imponerlas que, guardando proporción, produzca una impresión más eficaz y duradera sobre los ánimos de los hombres y la menos dolorosa sobre el cuerpo del reo. (BONESANA MARQUEZ DE BECCARIA, 2004).

El Manual sobre programas de Justicia Restaurativa de la Oficina de naciones Unidas Contra la Droga y El Delito define la Justicia Restaurativa como: "una forma de responder al comportamiento delictivo balanceando las necesidades de la comunidad, de la víctima y de los delincuentes". Así mismo ilustra sobre los diferentes términos utilizados para definir la Justicia Restaurativa entre los que se encuentran; Justicia Comunitaria, Justicia Positiva, Justica Relacional, justicia Reparadora entre otros y variando de acuerdo a la dificultad de traducción de su idioma de origen. (VASQUEZ BERMEJO, 2006).

Pero es en el contexto colombiano donde un modelo basado en la justicia restaurativa adquiere vital importancia para moldear la interrelación humana en un contexto social, así pues, la justicia restaurativa consiste en un proceso por el cual todas las partes que tienen interés en un determinado conflicto se juntan para resolverlo colectivamente y para tratar sus implicaciones a futuro. (DOMINGO, 2011).

Como cita BERNARDO CARREÑO, en hacia un Estado Social de Justicia Restaurativa:

La proposición "obra del tal modo que uses la humanidad, tanto en tu persona como en la persona de cualquier otro, siempre como un fin al mismo tiempo y nunca solamente como un medio" (KANT, USTA 2014). Se presentó en nuestro actual modelo constitucional como uno de 
los subyacentes del Estado Social de Derecho que invirtió la ecuación política del Estado de Derecho basado en que él era el fin y las personas el medio. Es decir, ese estado globalizado debe ser un estado social de Justicia Restaurativa que cumpla con los fines más allá previstos por el estado social y democrático de derechos fundado en una visión constitucional contemporánea: el fin de todo el quehacer estatal, el hombre-Kant ya nos lo recordó-; el medio, el Estado. (Pags.145-146).

\section{Principios de la justicia restaurativa}

La Reparación Integral, que nace del movimiento a favor de la víctima y la recuperación de su papel en el proceso penal. En cuanto a este dogma BERNARDO CARREÑO cita a RONDON,2014 en Hacia un estado social de justicia restaurativa - 2015, que esta posee unos "elementos claves: la restitución, la indemnización, la rehabilitación, medidas de no satisfacción y garantías de no repetición, bajo la característica de una reparación adecuada, diferenciada, trasformadora y efectiva en sus componentes materiales-daño emergente, lucro cesante- $e$ inmateriales recuperación del proyecto de vida, restablecimiento de la víctima en el goce efectivo de sus derechos y la recuperación del estado de la vida, bajo principios de dignificación de la víctima, participación de las decisiones que las afecta, acción sin daño y atención o integral a las distintas consecuencia negativas". (Sánchez Ávila, 2016).

La función de la reparación no es solo una función individual del autor respecto de la víctima, sino también un fenómeno pacificador propio del derecho. La reparación penal no se puede confundir con la indemnización civil a las víctimas.

Ya que La voluntariedad en la reparación es un punto crucial, la reparación forma parte de un concepto de justicia negociada, aunque no por ellos es más rápida y la justicia reparadora se sitúa en el seno del derecho penal. (Fernández, 2015)

Acorde a lo anteriormente dicho, a mi parecer es de vital importancia el empoderamiento de la víctima dentro de un proceso de Justicia Restaurativa, este nuevo rol de la víctima es de vital importancia si lo que se busca es u perdón restaurador ${ }_{52}$, el papel activo de la víctima al interior del proceso penal, ayudara sin lugar a dudas, que las victimas recuperen la confianza en ellas mismas, en sus acciones, en sus decisiones, en su comunidad y en los sistemas de justicia, a través de un sistema que garantice su movilidad, su libertad y su capacidad para controlar su propia

52 En consecuencia, el empoderamiento de las víctimas y su posibilidad de ejercer un perdón restaurativo se encuentran condicionados a que los victimarios no sean parte de las estructuras del poder estatal y que tampoco sean protegidos por estas estructuras, ya que se puede generar una manipulación que impide un castigo acorde con el daño, y en el peor de los casos la obtención de un perdón inmerecido (RODRIGUEZ, 2012) 
existencia, es decir que la justicia restaurativa consiga ser un instrumento real que empodere a las víctimas. (PIÑERES, 2005).

\section{Características de los programas de justicia restaurativa}

El Manual sobre programas de Justicia Restaurativa de la Oficina de naciones Unidas Contra la Droga y El Delito, menciona las siguientes características que a su juicio deben contener los programas de Justicia Restaurativa. Entre los que encontramos los siguientes:

- Una respuesta flexible a las circunstancias del delito, el delincuente y la victima que permite que cada caso sea considerado individualmente.

- Una respuesta al crimen que respeta la dignidad y la igualdad de cada una de las personas, desarrolla el entendimiento y promueve la armonía social a través de la reparación de las víctimas, los delincuentes y las comunidades.

- Una alternativa viable en muchos casos al sistema de justicia penal formal y sus efectos estigmáticos sobre los delincuentes.

- Un método que puede usarse en conjunto con los procesos y las sanciones de la justicia penal tradicional.

- Un método que incorpora la solución de los problemas y está dirigido a las causas subyacentes del conflicto.

- Una metodología que motiva al delincuente a comprender las causas y efectos de su comportamiento y a asumir sus responsabilidades de una manera significativa.

- Una metodología flexible y variable que puede adaptarse las circunstancias, la tradición legal, los principios y filosofías de los sistemas nacionales de justicia penal ya establecidos;

- Una metodología adecuada para lidiar con muchos tipos diferentes de ofensas y delincuentes, incluyendo ofensas muy serias.

- Una respuesta al crimen que es particular mente adecuada para situaciones en que hay delincuentes juveniles involucrados, en las que un objetivo importante de la intervención es enseñar a los delincuentes valores y habilidades nuevas;

- Una respuesta que reconoce el papel de la comunidad como principal actor para prevenir, responder al delito y al desorden social.

Brito Ruiz en su libro justicia restaurativa, enumera una serie de objetivos o metas buscadas por la Justicia Restaurativa. Desde el enfoque de sus diferentes actores. (Britto Ruiz, 2010)

\section{En relación al victimario}

- Que enfrenten los hechos y sus consecuencias, es decir, que tome conciencia y asuma responsabilidades. 
- Que asuma el trabajo de reparar el daño ocasionado y no deje este a la víctima ni a la sociedad.

- Que tome conciencia de sus actos y las razones y condiciones que le llevaron a cometerlo.

- Que revalúe sus actuaciones no por el temor al castigo si no por la conciencia de sus consecuencias.

- Que comprenda que el trato digno y respetuoso que se le brinda en el proceso es parte de lo que la sociedad espera recibir de él.

\section{En relación a la victima}

- Que reciba atención privilegiada, el objetivo es reparar el daño que recibió.

- Que cambie el equilibrio de poder entre ella y el victimario, pues la justicia restaurativa entiende que para que ocurra el delito la victima está en desventaja de poder.

- Que no sufra nuevas victimizaciones en el proceso del tratamiento del delito romper así con estigmas y prejuicios.

- Que tome un papel activo en el proceso, y logre plantear sus demandas de reparación ante el victimario sin sufrir nuevas agresiones.

En cuanto a la víctima puedo agregar lo manifestado por Jorge Iván peña "la realización del acto de perdonar solo es posible si el victimario se arrepiente de sus acciones y solicita el perdón a las víctimas, de lo contrario adquiere un carácter de burla y vacuidad. Cuando se pide perdón y se pone en coside3racion otorgarlo, se parte del acto de buena voluntad, de tener la capacidad de perdonar; ya que existen situaciones donde se presenta una relación desigual entre víctima y victimario, supuestamente igualada por un soberano. Pero que en esencia es desigual y desequilibrada. (PASCUAL, 2012).

\section{En relación con la comunidad}

- Que participe activamente en la resolución del delito y genere espacios de seguridad para las víctimas y victimarios.

- Que a partir del manejo de los casos se propicien espacios de fortalecimiento a una ética de la convivencia

- Que tome conciencia de las bases culturales y estructurales de la violencia y el delito para que emprenda acciones de trasformación.

- Que acoja y proteja a las víctimas y abra espacios de reinserción a los victimarios para superar estimas y prejuicios.

En cuanto a la comunidad puedo agregar lo manifestado por Rodríguez Peña en EL PERDÓN Y LA FILOSOFÍA “donde toma lugar el perdón reconciliador, las comunidades políticas necesitan de la 
confianza mutua entre las personas que hacen parte de estas comunidades para poder funcionar. Los actos de violencia y los crímenes hacen que las personas pierdan la confianza y se disuelvan los lazos que permiten la cohesión social y así el perdón surge como elemento restaurador de estos lazos de confianza, pero necesita que la víctima perdone, que el victimario reconozca su crimen y pida perdón y que la comunidad política reconozca a la víctima" (PASCUAL, 2012)

\section{Contraparte constitucional}

Para entrar a analizar la viabilidad de implementar un modelo de justicia restaurativa en nuestro país es importante buscar los referentes necesarios contenidos en nuestra Constitución Política. En primer lugar, se observa en el preámbulo de la Constitución Política de Colombia incluye entre los fines del Estado el fortalecimiento de la "Unidad de la Nación" y la garantía de la "la vida, la convivencia, el trabajo, la justicia, la igualdad, el conocimiento, la libertad y la paz. Dentro de un marco jurídico, democrático y participativo que garantice un orden político, económico y social justo".

En el artículo 2 de la Constitución Política de Colombia consagra "que son fines esenciales del Estado entre otros el de asegurar la convivencia pacífica y la vigencia de un orden justo. Así mismo que las autoridades de la Republica están instituidas para para proteger a todas las personas residentes, en su vida, en su honra, bienes, creencias y demás derechos y libertades y lo más importante a mi parecer asegurar el cumplimiento de los deberes sociales del Estado y de los particulares.

En cuanto a sus principios fundamentales, se consagro que el Estado de Colombia se fundamenta en "el respeto de la dignidad humana, EN EL TRABAJO Y LA SOLIDARIDAD de las personas que la integran y en la prevalencia del interés general".

La paz, en definitiva, no es otra cosa que el respeto efectivo de los derechos humanos. Cuando la dignidad humana es atropellada por la violencia o el terror, se está dentro de una situación de guerra contra lo más sagrado he inviolable del hombre. "No puede haber paz, mientras a nuestro alrededor hay quienes asesinan, secuestran o hacen desaparecer" (Sentencia T 102, 1993) ${ }^{53}$.

Se traza una política cultural que desafía los significados hegemónicos de educación y democracia, en una cultura política fuertemente marcada por el neoliberalismo donde el acceso a derechos se concibe como responsabilidad del individuo más que del Estado. (Rodríguez, p. 273)

El ordenamiento jurídico asegura, además, el derecho al libre desarrollo de la personalidad, con las limitaciones que imponen los derechos de los demás y el ordenamiento jurídico; prohíbe de

53 C.P.C pág. $12-34$ edición sentenciat-102, marz.10/93M.P. CARLOS GAVIRIA DIAZ. 
forma expresa la esclavitud, la servidumbre y la trata de seres humanos en todas sus formas; garantiza las libertades de conciencia, de culto, de expresión, y paz, a la movilidad, al trabajo, a la libre elección de profesión u oficio, y garantizar las libertades enseñanza, aprendizaje, investigación y cátedra.

Así mismo dentro del marco garantista relativo a los derechos y garantías fundamentales que se ha expuesto, se reconoce la plena aplicación y prevalencia de los tratados y convenios internacionales ratificados por el congreso que reconozcan derechos humanos que no pueden ser limitados en los estados de excepción. El ejercicio de los derechos y libertades reconocidos en la constitución implica responsabilidades: cumplir la constitución y las leyes, respetar los derechos ajenos y no abusar de los propios, obrar conforme a los principios de solidaridad social, respetar y apoyar a las autoridades democráticas, defender y difundir los derechos humanos como fundamento de la convivencia pacífica, participar en la vida política, cívica y comunitaria del país, propender al logro y mantenimiento de la paz, colaborar con el buen funcionamiento de la administración de la justicia, proteger los recursos naturales y culturales del país y velar por I la conservación de un ambiente sano. (Artículo 95, ibid.). Ya que no puede haber leyes o, decisiones judiciales que se aparten los valores constitucionales e internacionales supremos, so pena de ser ilegitimas social y jurídicamente hablando. (BARRETO ARDILA, 2009). En Concordancia con el Articulo 247 de la constitución política colombiana que faculta a la ley para crear jueces de paz encargados de resolver en equidad conflictos individuales y comunitarios o su posible escogencia por votación popular.

Esta practicidad de be estar dada en un tiempo y espacio determinado y delimitados en tiempo, para ser verdaderas garantías de justicia, además no es justificable bajo ningún aspecto aplazar la toma de medias y decisiones jurídicas o que el estado no disponga de medios efectivos para inmediatizar la practicidad y efectividad de los derechos fundamentales mediante la promulgación de leyes que sancionen a los responsables de violaciones de dichos derechos. (jonas, 2015).

\section{Que dice la jurisprudencia internacional.}

Dentro de los grandes avances surgidos durante el desarrollo de las democracias, se encuentran décadas de esfuerzos a favor de los Derechos Humanos con el objetivo de lograr reconocimiento dentro de la constitución, pero esta positivización solo se logra a través de siglos de luchas para lograr un cambio radical en la concepción del ser humano y de su entendimiento de la moral de la vida.

Es así como surge una carta de derechos al final del siglo VIII (Declaración de los Derechos del Hombre y el Ciudadano 1789 y el Bill of Rights de la Constitución estadounidense. Con 
posterioridad a esta época y a consecuencia de las graves violaciones de los derechos humanos y crímenes considerados de lesa humanidad cometidos por el régimen Hitleriano durante la segunda guerra mundial surgen diversos textos constitucionales, con amplios mandatos sustantivos para el estado redactados en formas de derechos fundamentales. Entre los que tenemos la Constitución Española 1978 la brasileña 1988 y La Colombiana 1991, textos en los cuales; no se limita solo en delimitar competencias o separar poderes públicos, sino que además contiene altos niveles de normas "materiales" o sustantivas que condicionan la actuación del Estado por medio de la ordenación de ciertos fines y objetivos.

Así mismo dentro del marco garantista relativo a los derechos y garantías fundamentales que se ha expuesto, se reconoce la plena aplicación y prevalencia de los tratados y convenios internacionales ratificados por el congreso que reconozcan derechos humanos que no pueden ser limitados en los estados de excepción. El ejercicio de los derechos y libertades reconocidos en la constitución implica responsabilidades: cumplir la constitución y las leyes, respetar los derechos ajenos y no abusar de los propios, obrar conforme a los principios de solidaridad social, respetar y apoyar a las autoridades democráticas, defender y difundir los derechos humanos como fundamento de la convivencia pacífica, participar en la vida política, cívica y comunitaria del país, propender al logro y mantenimiento de la paz, colaborar con el buen funcionamiento de la administración de la justicia, proteger los recursos naturales y culturales del país y velar por la conservación de un ambiente sano. (Artículo 95, ibíd.). Ya que no puede haber leyes o, decisiones judiciales que se aparten los valores constitucionales e internacionales supremos, so pena de ser ilegitimas social y jurídicamente hablando. (Gomez Quintero, 2009).

De este modo se pone de presente que el beneficio de la pena alternativa no es inconstitucional en sí mismo, sino que resulta del análisis sistemático del procedimiento, por la desproporción entre los beneficios y los derechos de las víctimas, entre otros los privilegios de los que podrán gozar los miembros de este grupo son: ser amnistiados o indultados; participar en política de forma inmediata y en el ejercicio del poder público; no ser extraditados e incluidos los delitos conexos con el delito político. Por ello, no es improbable que el narcotráfico también sea incluido como un delito conexo. (BELTRÁN SIERRA, 2006).

\section{El acuerdo final para la terminación del conflicto y la construcción de una paz estable y duradera (acuerdos de la habana).}

Contempla un listado de sanciones teniendo en cuenta (a) el grado de verdad otorgado por la persona. (b) la gravedad de la conducta sancionada. (c) el nivel de participación y responsabilidad y (d) los compromisos en materia de reparación a las víctimas y garantías de no repetición.

En este orden de ideas las sanciones están clasificadas en tres grupos: 
1- Sanciones aplicables a quienes reconozcan verdad exhaustiva, detallada y plena en sala de reconocimiento de verdad y responsabilidad.

2- Sanciones aplicables a quienes reconozcan verdad y responsabilidad por primera vez en el proceso contradictorio ante la sección de primera instancia del tribunal para la paz antes de dictar sentencia.

3- Sanciones aplicables a quienes no reconozcan verdad y responsabilidad en el proceso contradictorio ante la sección de primera instancia del tribunal para la paz y resulten declarados culpables por este. (tomado del texto original).

Para el caso específico de este articulo las sanciones aplicables para el numeral (1), manifiesta en el numeral 60 de los acuerdos, que las sanciones tienen que estar encaminadas esencialmente a satisfacer los derechos de las víctimas, consolidar una paz estable y duradera, así mismo que debe tener la mayor función restaurativa y reparadora del daño causado, siempre en relación con el grado de reconocimiento de verdad y responsabilidad que se haga ante el componente de SIVJRNR (Sistema Integral De Verdad, Justicia, Reparación Y No Repetición). (Tomado del texto original).

Así mismo los miembros de las Farc comparecientes ante las sala SIVJRNR, podrán presentar un proyecto detallado, individual o colectivo, de ejecución de los trabajos, obras o actividades reparadoras y restaurativas, endicho proyecto se deben indicar obligaciones, objetivos, fases temporales, horarios y lugares de la ejecución, así como las personas que los ejecutaran, y el lugar donde residirán las sanciones impuestas por el tribunal pres establecerán los lugares donde residirán las personas que ejecutaran los proyectos. El proyecto que no puede ser incompatible con las Políticas Públicas de Estado podrá incluir entre otros trabajos dependiendo del lugar de ejecución los siguientes: (ver tabla anexa 1)

\section{CONCLUSIONES}

Los compromisos de verdad, justicia, reparación y garantías de no repetición. Deben estar ligados teleológicamente a la política y al perdón. La primera se enmarca dentro del ámbito de creación del andamiaje jurídico necesario en cuanto a mecanismos y garantías dentro de un proceso de reconciliación se refiere. En Colombia el entramado jurídico está bien documentado entre estas están:

La Ley de Justicia y Paz -Ley 975 de 2005ㄹ, Decreto 976 del 9 abril de 1997¹, La Ley 387 de 24 julio de $1997^{1}$, La Ley 418 de $1997^{1}$, La Ley 589 del 6 de julio de $2000^{1}$ y la Ley 1190/2008 entre otros.

Históricamente las Farc adelantaron negociaciones con diferentes gobiernos entre los que se encuentran los de Julio Cesar Turbay (1978-1982), Belisario Betancur (1982-1984) que 
desembocaron en los acuerdos de la Uribe, Cesar Gaviria (1990 - 1994). Hoy bajo el gobierno de Juan Manuel Santos y foco de este articulo el Acuerdo Final para La Terminación del Conflicto y la Construcción de una paz estable y duradera más conocidos como (acuerdos de la Habana). Más exactamente en lo que se refiere a las sanciones aplicables en zonas rurales a quienes reconozcan verdad exhaustiva, detallada y plena.

Como mencione en otro aparte, el perdón restaurador es un requisito de la justicia restauradora, pero este está más ubicado en la esfera de lo subjetivo y como tal no puede ser exigido, es natural y espontaneo. Así como existen diferentes tipos de perdón; el perdón redentor, el perdón incondicional el perdón condicionado, el perdón retributivo, el perdón reconciliador y el perdón restaurativo (PASCUAL, 2012) este último más en sintonía con la temática de la justicia restaurativa tema de este artículo.

En este orden de ideas, dentro de un paradigma de Justicia Restaurativa, para que el empoderamiento de las víctimas sea real es menester el cambio en los roles y costumbres de los modelos en la justicia penal tradicional, a groso modo implica que tanto el aparato de justicia, como el ofensor, la comunidad y las víctimas, deberán encarar cambios en los paradigmas respecto a las formas de hacer y ejercer la justicia, y movilizarse a través de acciones que fortalezcan las relaciones sociales que han sido devastadas por el delito. (PIÑERES, 2005)

Las medidas trasformadoras subyacentes implican desmontar los esquemas de poder, discriminación y marginación que facilitaron la victimización, con el fin de evitar una eventual Re victimización, y sentar las bases para la reconciliación en el país. El enfoque trasformador orienta las acciones y medidas hacia la profundización de la democracia y el empoderamiento de las capacidades de las personas en el marco de la recuperación de la confianza en las instituciones, al tiempo que orienta la recuperación o reconstrucción de un proyecto de vida digno y estable de las víctimas. (Fernández, 2015)

Ahora bien, centrados en el tema de las Sanciones aplicables a quienes reconozcan verdad exhaustiva, detallada y plena en sala de reconocimiento de verdad y responsabilidad. Los acuerdos de la habana contemplan que los proyectos deberán establecer un mecanismo de consulta con los representantes de las victimas residentes en el lugar de ejecución de dicho proyecto, con lo que se buscaría que la víctima haga parte del proceso de justicia restaurativa, entendiendo que no se puede llegar a una reparación que satisfaga las necesidades de la víctima si no se incluye y se protege durante el proceso de toma de decisiones.

Esta asistencia puede ocurrir de dos formas: derecho de participación de la víctima durante todo el procedimiento judicial y la asistencia de la víctima en el proceso de recuperación de las 
consecuencias del delito que fue objeto. Se propende con esto que la solución encontrada satisfaga la necesidad de retribución del estado, sin dejar de realizar reparación a la víctima. (DUYMOVICH, 2007).

Por consiguiente, las víctimas actuales o potenciales de un delito deben estar seguras ante cualquier contingencia tendrían acceso a los recursos que permitirán su reparación. Las víctimas se sentirán empoderadas en la medida en que sienten que son importantes para el sistema penal, que el Estado garantiza su acceso gratuito y oportuno a servicios de salud física y mental, y que cuentan con el apoyo de una red social y de su comunidad. (PIÑERES, 2005).

La justicia restaurativa plantea que los delitos que ocurren en el seno de una comunidad contra miembros de una comunidad y en ese sentido el que asuma la resolucion como una relacion entre delincuente y la victima con el acompañamineto de la comunidad, resulte en un proceso que facilite mucho mas la eficacia de la sancion. Como consecuenbsia de la sensibilizacion por parte del victimario de los daños causados a la victima y de los alcances de estos, ante esto cabe la posibilidad de que no se recaiga en la conducta dañina y se restablezcan los lazos con la comunidad. La justicia restaurativa representa un cambio en el modelo retributivo. Con el que se busca que el centro del proceso restaurador sea la victima y junto con el infracto con las garantias estatales se busque la reparacion de los daños y y la restauracion de los protagonistas con la sociedad. (Britto Ruiz, 2010).

Con todo lo anteriormente expuesto se puede concluir que se hace necesario el empoderamineto de la victima del proceso de Justicia Restaurativa, el respaldo del Estado para despojar al victimario de su rol de superioridad ante las victmas y una concientizacion verdadera del victimario de los alcances de sus acciones y del daño acusado por estas ${ }^{54}$.

Sin estos tres pilares no se hace posible la Justicia Restaurativa. Entonces los "acuerdos de la habana" en lo que a sanciones a quienes reconozcan verdad exhaustiva se refiere, contempla dos roles para los excombatientes, un rol de ejecutor y un rol de participacion de proyectos de acuerdo al texto citado.

Pero asi mismo en establece la creacion del Planes integrales comunitarios y municipales de sustitución y desarrollo alternativo (PISDA). Que según lo contempla en los acuerdos serán los encargados de adelantar lo concerniente como su nombre lo indica a los planes de sustitución de cultivos ilícitos.

54 En consecuencia, el empoderamiento de las víctimas y su posibilidad de ejercer un perdón restaurativo se encuentran condicionados a que los victimarios no sean parte de las estructuras del poder estatal y que tampoco sean protegidos por estas estructuras, ya que se puede generar una manipulación que impide un castigo acorde con el daño, y en el peor de los casos la obtención de un perdón inmerecido (RODRIGUEZ,2012) 
En este sentido como complemento contempla la creación de Programa nacional integral de sustitución de cultivos de uso ilícito (PNIS) (ver tabla anexa 3), dependiente del anterior que tendrán presencia en las regiones y municipios y estarán representados por concejos territoriales conformados así:

\section{Concejos territoriales (ver anexo 2)}

Estos concejos territoriales podrán contar con funcionarios a nivel local y Podrán estar compuestos por miembros de las FARC-EP en proceso de reincorporación o reincorporado a la vida civil. Que entre otras funciones podrán:

- Ejecutar los planes concertados de sustitución y recuperación ambiental de las áreas afectadas por cultivos de uso ilícito, de acuerdo con los lineamientos de la Dirección General.

- Brindar asistencia técnica a las asambleas comunitarias en la construcción de la visión territorial integral, sistematizarla y divulgar el resultado final a la comunidad.

- Informar la visión territorial integral construida por las asambleas comunitarias al Consejo Asesor Territorial, al Director General y el Consejo Permanente de Dirección, (CesPaz, s.f.).

Todas las anteriores funciones o atribuciones están lejos de favorecer un enfoque en las victimas como lo contempla la Justicia Restaurativa ya que directamente colocan en situaciones dispares a la víctima y al victimario, siendo este último gestor, administrador y ejecutor de los presupuestos destinados para las restauraciones de las víctimas lo que claramente es una posición superior en comparación con las atribuciones otorgadas a la víctima como son:

- Realizar seguimiento al cumplimiento del PNIS y sus objetivos.

- Realizar seguimiento al cumplimiento de los PISDA.

- Verificar la ejecución presupuestal del PNIS y los PISDA.

Meras funciones de veedurías ciudadanas sin salarios, poder de decisión, gestión o administración colocando en un campo inoperante y de aparente empoderamiento a las víctimas de grupos armados y del estado.

BRITO RUIZ, dice de la autonomía y el empoderamiento que en las situaciones llamadas por ella "típicas" en las relaciones donde se ven envueltos menores de edad ya sean víctimas o victimarios, dice que hay que combinar los elementos de "control y apoyo" pero con un enfoque diferente ya que no se puede tratar a la víctima igual que al victimario. Manifiesta que en el caso del ofensor hay que buscar la autonomía y en el caso de la víctima el empoderamiento. De esta 
manera el ofensor al logra autonomía entendida desde el punto de vista de la madures de auto colocarse reglas y conductas para no reincidir en las conductas dañinas, reglas y conductas que deben ser respetadas preparando así a las nuevas generaciones para que también puedan gobernarse a sí mismos. En cuanto a la víctima BRITO sostiene que es un poco diferente en el sentido de tener el Control Y Apoyo, la victima requiere más apoyo emocional en comparación con el ofensor, no olvidemos en quien se centra la Justicia Restaurativa ya que es uno de los pilares fundamentales de la Justicia Restaurativa. En el caso del control hace énfasis en la situación de desequilibrio de poder pues la agresión solo es posible si el ofensor se siente superior y más fuerte en relación a la víctima. (Britto Ruiz, 2010).

Rodríguez peña, ¿comenta que "como ejercer el perdón cuando no se reconoce el daño?, ¿ni a la víctima? Para que la víctima perdone es necesario que sea empoderada y ese empoderamiento contempla varios niveles: volver a ser lo que era antes de ser victimizado, el reconocimiento social del sufrimiento y las vejaciones las cuales fueron sometidas las víctimas, la garantía de que el estado reforme su aparato legislativo con el fin de prevenir la repetición de esos hechos y lo más importante la participación activa de la víctimas, no como espectador, si no desde una posición más ventajosa, y al mismo tiempo el estado debe mermar la capacidad de poder del victimario. (PASCUAL, 2012)

El empoderamiento trata de "dar poder a las víctimas para dar lograr el empoderamiento no existen reglas a seguir lo que importa es que las personas a cargo generen un clima de seguridad y confianza necesarios para que la víctima sientan el acompañamiento, pero igualmente que asuman un nuevo rol y no se caiga en una situación de subvaloración que no favorece a las víctimas ya que una cosa es solidaridad y otra muy diferente lastima" (Britto Ruiz, 2010)

Mediante el empoderamiento se busca dar poder a las víctimas para que puedan ser, hacer y decidir por sí mismas, es un proceso en ubicado en las relaciones políticas que implica dar autonomía a las comunidades, para que estas reconstruyan y fortalezcan su tejido social desgastado por el delito. (Melissa J. Ferguson sitado por Crespo Patricio, 2007)

Lao-Montes en la noción democracia sustantiva, reflexiona sobre el origen de las desigualdades sociales, al tiempo invita a la elaboración de políticas sociales en favor de la equidad, que al unísono ayuden al empoderamiento de las comunidades excluidas históricamente, en su concepto manifiesta que la democracia es mucho más que la participación en procesos electorales y el reconocimiento de derechos civiles contra un poder abrumador del estado, así pues el empoderamiento viene a ser en sus palabras "una participación activa y un poder decisivo en todos los ámbitos de la vida social y cultural. Concebida como proceso de poder colectivo o empoderamiento popular" (LAO-MONTES, 2013) 
En este sentido, Sáez, destaca la participación activa de la víctima en la resolución de los conflictos, pero que esta tenga certeza de que se podrá expresar en libertad y seguridad según necesite y que al mismo tiempo tiene garantías de ser escuchada. Disminuyendo los riesgos de una victimización segundaria ya que el trato a la víctima de un delito debe ser considerablemente mejor al ser esta el centro de la justicia restaurativa, con lo que se busca mitigar los daños emocionales y la perdida que sigue al daño sufrido.

La reparación que incluye recepción de disculpas y la compensación material por los daños causados, refleja o evidencia la necesidad de controlar o verificar el grado de cumplimiento del acuerdo adoptado, en especial de las actividades que se diluyen en el tiempo de su ejecución. (RAMON SAEZ, 2010)

Hay que tener especial cuidado cuando el perdón se convierte en un mero acto político, sin las características requisitos necesarios para garantizar una justicia restaurativa pensada para las víctimas, es mejor no utilizar la palabra perdón, ya que existe una brecha entre este y el ordenamiento jurídico, este distanciamiento solo se puede abordar cuando hay una verdadera conciencia de la responsabilidad histórica, cuando el victimario ha interiorizado el alcance dañino de sus actos. (PASCUAL, 2012)

En este orden, todo modelo de Justicia Restaurativo tiene que tener su origen y fin en la víctima, de sus necesidades y deseos, garantizando que las decisiones que las personas víctimas sean respetadas. La justicia debe buscar que las personas que alguna vez fueron victimizadas y re victimizadas sientan que son realmente las protagonistas, que la agresión de la que fueron objeto no será un obstáculo para que puedan seguir actuando con control de sus vidas, que puedan salir a la calle con la frente en alto, seguras, confiadas, seguras de que pudieron lograr algo por ellas mismas, con la protección y acompañamiento del Estado y de su comunidad, que no fueron invisibles, que su voz fue escuchada y su dolor reparado. Pero igualmente ese empoderamiento que se puede dar a través de la Justicia Restaurativa, no debe llevar a que las víctimas se conviertan en futuros victimarios, el poder debe ser un poder que permita hacer cosas con otros, por y para otros y no sobre otros. (PIÑERES, 2005).

Hay que tener muy presente que hacer mediación en lo penal no es lo mismo que hacer mediación en otro tipo de conflicto, ya que cuando se habla de "delito" no solo se habla de un conflicto entre partes si no de un daño de carácter intencional, donde el ofensor actuó con la voluntad de hacer daño o por negligencia producida dentro del contexto de una relación humana, lo que implica que el daño conlleva en su interior un componente de injusticia. En este sentido la preocupación está en una segunda victimización producto de la confrontación de la víctima con su ofensor en una situación donde las disculpas son dudosas (BOLIVAR, 2017) 
Por último, en su conferencia de posconflicto ¿justicia y perdón, derecho o ética? Michel Wieviorka (Wieviorka, 2014) expone los límites de la Justicia Restaurativa entre los que encontramos:

1. No basta con reparar económicamente a la víctima, ya que de ser así se el proceso de Justicia Restaurativa corre el riesgo de sufrir una privatización o comercialización de la pena y generar focos de corrupción e impunidad. Al igual que debe incluir a la sociedad que ha sido víctima esto es trascender más allá de la esfera individual de la víctima.

2. El papel relevante del estado en la acción penal, que el estado como garante de la Justicia Restaurativa controle y administre los elementos de la restauración y esta sea avalada por un juez afín de velar por los presupuestos materiales de la mediación.

3. Que no sea obligatoria, que tanto víctima como agresor comparezcan de manera libre y voluntaria. Pero también hay que tener en cuenta la posición desigual de las partes que podrá afectar de forma real el proceso.

Y también expone sus puntos de vista en relación a las fallas que se pueden presentar en los procesos de Justicia Restaurativa, a los que él denomina "el utilitarismo de la Justicia Restaurativa" esto relacionado con la desviación de los objetivos y fines de la Justicia Restaurativa, que ya no estarían enfocada en la victima sino por el contrario tendría un enfoque económico al ser una Justicia más económica procesalmente hablando. Y al ser más expedita corre el riesgo también de ser utilizada con fines de descongestionar los despachos sacrificando sus principios y así las mismas Justicia Restaurativa.

En este mismo sentido Las etapas donde intervienen las victimas también presuponen un riesgo, ya que la escasa preparación de los profesionales, las etapas de mediación y el manejo de las expectativas de la justicia Restaurativa conllevarían a la instrumentalización de la víctima en el encuentro restaurativo además de una baja o nula compensación económica. Sumado al riesgo de que el delito sea minimizado mediante presión (para que la víctima se vea obligada a aceptar disculpas o una solución instrumentalizada, donde las inquietudes de las víctimas no tengan respuesta real. (Vanfraechem, 2015).

Se han detectado otros riesgos dentro de los procesos de justicia restaurativa, una evaluación de prácticas de Justicia Restaurativa en Estados Unidos, mostro que la mayoría de los casos de Justicia restaurativa no solo eran iniciados del lado del ofensor sino que la agenda del proceso era manejada por estos, de este modo resulta que una práctica o traje hecho a la medida del ofensor da como resultado una segunda victimización ya que las necesidades de la víctima quedan relegadas a segundo plano, replicando con esto la principal falla de los modelos de justicia actuales. (DANIELA BOLIVAR sitando a MIKA ET AL, 2011) 
Como lo plantea Gutiérrez (2014, p. 193) el proceso de mini reformas agrarias que registra el país con cada programa de gobierno que hace alusión a la entrega de tierras a diferentes tipos de población no resuelve el problema.

Por otro lado, uno de los objetivos de la Justicia Restaurativa es devolver el conflicto a la comunidad, se trata de una "Justicia Comunitaria" para que esta le encuentre solución al caso. En la Justicia Restaurativa permanecen vestigios del derecho Penal Estatal, que nace con las monarquías absolutas que convierten cualquier delito en una ofensa contra el Rey, alienando el conflicto de la comunidad. Delegando por ende la responsabilidad de la prevención de este en el estado. En respuesta a esto y rescatando mecanismos de la justicia indígena de pueblos aborígenes de Oceanía, Latino América o África la Justicia Restaurativa busca el fortalecimiento de la comunidad, dotándola de poderes para que esta tenga mayor protagonismo en la resolución de conflictos, y sobre todo sea capaz de evitarlos en el futuro. (ADAN NIETO MARTINEZ, 2008).

\section{BIBLIOGRAFÍA}

NIETO, Martinez Adam (2008). Auto Regulacion y Sanciones. En L. A. Jimenez. Lex Nova. Recuperado el 2017, de:

https://books.google.com.co/books?id=yLkFmW1dcsEC\&pg=PA111\&lpg=PA111\&dq=riesgos+de + la+justicia+restaurativa\&source=bl\&ots=nq6t2Pm2E9\&sig=CjatGvMN9nNt3 jtBZgGC CJ9o0\&h l=es\&sa=X\&ved=0ahUKEwiFOr70u jWAhWEdSYKHXaEBFQ4FBDoAQgoMAE\#v=onepage\& $q \& \mathrm{f}=\mathrm{fa}$ $\underline{\text { IsE }}$

BARRETO Ardila, H. (2009). las Victimas en el proceso de justicia y paz carácter simbólico de la verdad, la justicia y la reparación en la transición hacia la convivencia tolerante. DIALNET, 17-36.

BELTRÁN Sierra, A. (2006). Sentencia c-400. Bogotá.

BOLIVAR, D. s. (17 de 10 de 2017). La víctima en la justicia restaurativa. Análisis. Obtenido de: Researchgate:file:///C:/Users/gucampiz/Downloads/BolivarD.2011Lavctimaenlajusticiarestaurat iva.pdf

BONESANA Marquez DE Beccaria, C. C. (2004). De los delitos y las penas 1974. Madrid: Juristas Universales.

BRITTO Ruiz, D. (2010). Justicia restaurativa: Reflexiones sobre la Experiencia de Colombia. Loja: Coleccion Cultura de la Paz.

CESPAZ. (s.f.). Presentación PNIS. Obtenido de: 
Gustavo Campiz Jiménez

\section{http://www.marchapatriotica.org/images/nuevaweb/archivos/presentacion PNIS.pdf}

CID Moline, J. (2009). Medios alternativos de solucion de conflictos y derecho penal. Revista de Estudios de la Justicia, 111-130.

BOLIVAR Daniela, citando a MIKA ET AL, 2. (Enero de 2011). RESEARHGATE. Obtenido de https://www.researchgate.net/publication/215676867

DOMINGO, V. (Noviembre de 2011). Contexto teórico - práctico de la justicia restaurativa en Europa con especial atención a España. Ponencia impartida en el congreso internacional, "CIENCIA PENAL Y JUSTICIA PENAL RESTAURATIVA", Noviembre de 2011, Guayaquil (Ecuador). Guayaquil, Ecuador.

DUYMOVICH, R. I. (2007). La reparación integral como mejor alternativa de satisfacción a la víctima: experiencias de la justicia restauradora en casos de delincuencia juvenil y violaciones a los derechos humanos. Lima: Instituto De Ciencia Procesal Penal (INCIPP) Programa De Formación A Jóvenes Investigadores.

ESQUINAS Valverde, P. (2005). La mediacion entre la victima y el agresor como forma alternativa de resolucion del conflicto. Obtenido de:

http://uhu.es/revistapenal/index.php/penal/article/viewFile/285/275

FERNÁNDEZ, M. A. (01 de 06 de 2015). Revista Internacional de Doctrina y Jurisprudencia. (L. M. Justicia, Productor, \& Revista Internacional de Doctrina y Jurisprudencia) Obtenido de: https://w3.ual.es/revistas/RevistalnternacionaldeDoctrinayJurisprudencia/pdfs/201409/articulo s-mediacion penal.pdf

GOMEZ Quintero, A. (2009). La administracion de justicia en el marco del proceso de paz colombiano. Madrid.

GUTIÉRREZ, J. (2014). Costos sociales de transacción de la Ley de Restitución de Tierras en Colombia: Un país sin Reforma Agraria. Jurídicas CUC, 10 (1), 157 - 196.

JONAS, A. E. (2015). La reparacion integral como derecho de las victimas. Bogota: Grupo Editorial Ibañez. Recuperado el 2016 
LAO-MONTES, A. (2013). Empoderamineto, descolonizacion y democracia sustantiva. afinando principios etico-politicos para las diasporas afroamericanas. Obtenido de Scielo org: http://www.scielo.org.co/pdf/recs/n12/n12a03.pdf

MÁRQUEZ, Cárdenas Á. E. (Julio-Diciembre de 2007). La justicia restaurativa versus la justicia retributiva en el contexto del sistema procesal de tendencia acusatoria. Prolegomenos, 201-212.

MARQUEZ, C. A. (2007). La justicia restaurativa versus la justicia retributiva en el contexto del sistema procesal de tendencia acusatoria. PROLEGOMENOS. Derechos y valores, 201-212.

Ferguson J. Melissa citado por Crespo Patricio, d. R. (2007). Empoderamiento concepto y orientaciones. Obtenido de: http://www.asocam.org/biblioteca/ASO RA Empoderamiento.pdf

PADILLA Villarraga, A. (2011). Mediacion penal y justicia juvenil restaurativa. Revista de Psicologia Juridica, 39-52.

PASCUAL R. E. (2012). La mediación en el sistema penal. Tesis Doctoral. Madrid, España: Universidad Complutense De Madrid. Obtenido de: http://eprints.ucm.es/16592/1/T33979.pdf

PIÑERES, C. G. (2005). Psicología Jurídica Y Forense. Obtenido de:

\section{http://psicologiajuridica.org/psj117.html}

RAMON Saez, C. S. (2010). La mediación penal dentro del proceso. análisis de situacion. propuesta de regulacion y autorregulacion. protoclos de evaluacion. documento ideologico: analisis desde la perspectiva de la politica criminal y del derecho a la tutela judicial efectiva. Cataluña y Euskadi: Concejo General del Poder Judicial.

RODRíGUEZ, P. J. (1 de enero de 2012). El perdón y la Filosofía, 84. (u.d. Rosario, Ed.) Bogota, Colombia: Universidaed del Rosario. Obtenido de http://eprints.ucm.es/16592/1/T33979.pdf

RODRÍGUEZ, E. (2014). La protesta social en el primer gobierno de Juan Manuel Santos. Jurídicas CUC, 10 (1), $233-281$.

SÁNCHEZ Ávila, L. K. (2016). Justicia restaurativa: integración efectiva de las partes en el sistema penal. Tesis de Maestria en Derecho con profundización en Derecho penal. Bogota, Colombia: Universidad Nacional de Colombia.

SENTENCIA T 102 (CPC Marzo de 1993). 
SISTEMA NACIONAL DE SEGURIDAD CIUDADANA (SINASEC) \& Apoyo opinión y Mercado. (Enero de 2005). Estudio de victimizacion en las ciudades de Lima, Arequipa, Cusco, Huamanga, Iquitos y Trujillo. Recuperado el Agosto de 2017, de: https://www.oas.org/dsp/documents/victimization surveys/peru/per\%C3\%BA\%20\%20estudio \%20de\%20victimizaci\%C3\%B3n\%202005.pdf

KALACH, G. (2016). Las comisiones de la verdad en Colombia (2016) Revista Jurídica Mario Alario D’Filippo. VIII, (16): 106-124. Recuperado de DOI: https://doi.org/10.32997/2256-2796- vol.8num.16-2016-1534

VANFRAECHEM, D. B. (4 de octubre de 2015). Víctimas en justicia restaurativa: ¿sujetos activos o en necesidades? un estudio europeo desde la perspectiva del operador social. Universitas Psychologica, 4, 23. Recuperado el 2017, de:

http://www.redalyc.org/articulo.oa?id=64744107019

VASQUEZ Bermejo, O. (Febrero de 2006). ¿Qué es la justicia juvenil restaurativa? Recuperado el Agosto de 2017, de http://www.justiciaparacrecer.org/

Wieviorka, M. (2014). Posconflicto ¿justicia y perdon, derecho o etica? Banco de la Republica.

Zuñiga Rodriguez, L. (2006). Criminalidad organizada, derecho penal y sociedad: apuntes para el análisis. En N. S. (coord.), El desafio de la criminalidad organizada (págs. 39-68). Salamanca: Congreso Universitario de Alumnos de Derecho Penal.

ZUÑIGA, R. L. (2015). Modelos de política criminal frente a la criminalidad organizada: entre eficacia y garantías. Revista General de Derecho Penal.

Decreto 976.9 abril de 1997

Ley 975 de 2005

Ley 387 de 24 julio de 1997

Ley 418 de 1997. Diciembre 26

Ley 589 del 6 de julio de 2000

Ley $1190 / 2008$.

DERECRETO 893 DEL 28 DE MAYO DEL 2017. "Por el cual se crean los Programas de Desarrollo con Enfoque Territorial: PDET

Acuerdos de la Habana

Hacia un estado social de justicia restaurativa (Bernardo Carreño-2015) 
La reparación integral como derecho de las victimas (Alfredo Cáceres Mendoza)

Compilación de instrumentos internacionales (Naciones Unidas, octava edición 2012)

\section{TABLA ANEXO 1}

Sanciones Contempladas En El Acuerdo Final Para La Terminación Del Conflicto Y La Construcción

De Una Paz Estable Y Duradera (Acuerdos De La Habana). Para Quienes Reconozcan Responsabilidad.

\section{A- EN ZONA RURAL}

1. Participación/ejecución en programas de reparación efectiva para los campesinos desplazados.

2. Participación/ejecución de programas de protección medio ambiental de zonas de reserva.

3. Participación/ejecución de programas de construcción y reparación de infraestructuras en zonas rurales; escuelas, carreteras, centros de salud, viviendas, centros comunitarios, infraestructuras de municipios.

4. participación/ejecución de programas de desarrollo rural.

5. participación/ejecución de programas de eliminación de residuos en las zonas necesitadas de ello.

6. participación/ejecución de programas de mejoras de la electrificación y conectividad en comunicaciones de la zona agrícolas.

7. participación/ejecución de programas de sustitución de cultivos ilícitos.

8. participación/ejecución de programas de recuperación ambiental de las áreas afectadas por cultivos ilícitos.

9. participación/ejecución de programas de construcción y mejora de las infraestructuras viales necesarias para la comercialización de productos agrícolas de zonas de sustitución de cultivos ilícitos.

10. participación/ejecución de programas. (Tomado del texto original)

\section{B- EN ZONAS URBANAS}

1. participación/ejecución de programas de construcción y reparación de infraestructuras en zonas urbanas; escuelas, vías públicas, centros de salud, viviendas centros comunitarios infraestructura de municipio.

2. participación/ejecución de programas de desarrollo urbano.

3. participación/ejecución de programas de acceso a agua potable y construcción de redes y sistemas de saneamiento.

(Tomado del texto original) 
C- LIMPIEZA Y ERRADICACIÓN DE RESTOS EXPLOSIVOS DE GUERRA, MUNICIONES SIN EXPLOTAR Y MINAS ANTIPERSONALES DE LAS ÁREAS DEL TERRITORIO NACIONAL QUE HUBIESEN SIDO AFECTADAS POR ESTOS ARTEFACTOS.

1. participación/ejecución de programas Limpieza y erradicación de restos explosivos de guerra, municiones sin explotar

2. participación/ejecución de programas de limpieza y erradicación de minas antipersonas y artefactos explosivos improvisados.

(Acuerdo Final Para la Terminación del Conflicto y La Construcción De Una Paz Estable y Duradera paginas 130-160. (Acuerdos de la habana).

\section{TABLA ANEXO $\mathbf{N}^{\circ} \mathbf{2}$}

\section{CONSEJOS ASESORES TERRITORIALES}

\section{INTEGRANTES}

\section{DELEGADOS DE} AUTORIDADES TERRITORIALES

\section{DELEGADOS DEL GOBIERNO NACIONAL}

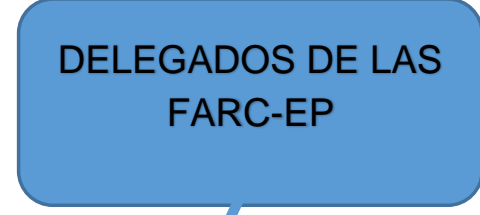

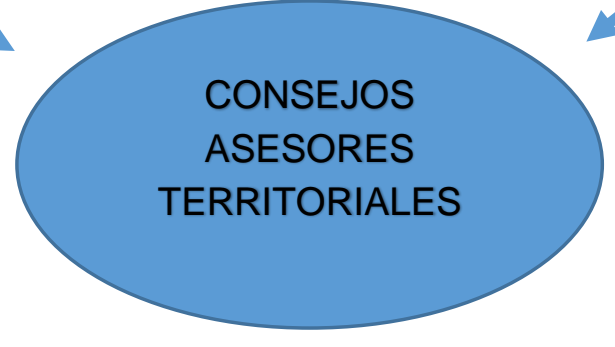

DELEGADOS DE ORGANIZACIONES CAMPESINAS TERRITORIALES
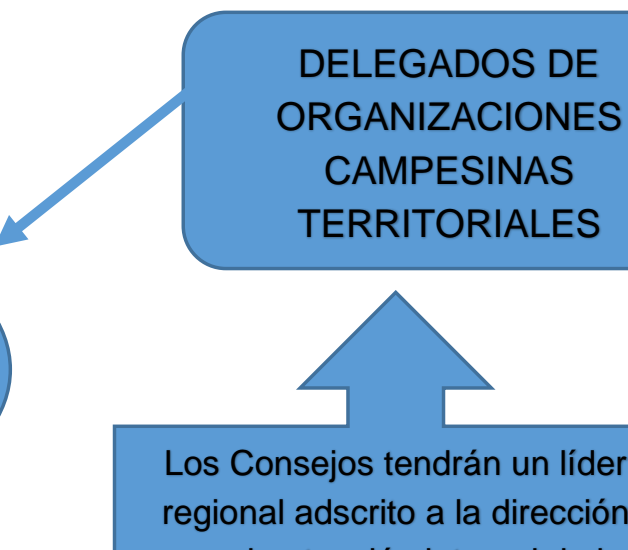

Los Consejos tendrán un líder regional adscrito a la dirección para la atención integral de la lucha contra las drogas.

\section{TIENE COMO OBJETIVOS}

- Ejecutarán las funciones del Consejo Municipal de Evaluación y Seguimiento, y Comisiones Municipales de Planeación Participativa, contempladas en el punto 4.1.3.5 del Acuerdo de Paz. (CesPaz, s.f.) 
